\title{
Recognizing the Symptom Spectrum of Narcolepsy to Improve Timely Diagnosis: A Narrative Review
}

\author{
Laury Quaedackers (iD) \\ Sigrid Pillen (D)' \\ Sebastiaan Overeem (iD) ${ }^{2}$ \\ 'Sleep Medicine Center Kempenhaeghe, \\ Heeze, the Netherlands; ${ }^{2}$ Biomedical \\ Diagnostics Laboratory, Department of \\ Electrical Engineering, Eindhoven \\ University of Technology, Eindhoven, the \\ Netherlands
}

\begin{abstract}
Narcolepsy is a chronic sleep disorder with a strong negative impact on quality of life, especially when untreated. Diagnostic delay is a persistent problem, with obvious detrimental effects on patients. A diagnosis of narcolepsy may be delayed because of its broad symptom presentation which is much more encompassing than the classical "tetrad" of sleepiness, cataplexy, hallucinations, and sleep paralysis. Furthermore, symptoms can vary over time. Presentation of symptoms can also be markedly different between children and adults. Finally, common sleep-related comorbidities increase the risk of narcolepsy being masked by overlapping symptoms or treatment. In this review, we provide a detailed description of the broad and dynamic symptom spectrum of narcolepsy, with specific attention to the different manifestations in both adults and children. The overarching goal is to help not only sleep specialists, but general practitioners, pediatricians, and other caregivers with early recognition and prompt diagnosis of this severe but treatable disorder. Keywords: narcolepsy type 1, cataplexy, screening, diagnosis, diagnostic delay, polysomnography, pediatrics
\end{abstract}

\section{Introduction}

Narcolepsy is a chronic neurologic sleep disorder with an estimated prevalence of 25-50 per $100,000 .^{1}$ It is caused by defects in hypocretin (orexin) neurotransmission, most likely through an autoimmune-mediated destruction of hypocretin cells in the dorsolateral hypothalamic region. ${ }^{2}$ Clinicians may be relatively familiar with the classic description of four primary narcolepsy symptoms resulting in a "tetrad": excessive daytime sleepiness (EDS), cataplexy, sleep paralysis, and hypnagogic hallucinations. Others may even recognize the narcolepsy "pentad", adding nocturnal sleep fragmentation as a key symptom. However, most patients do not present with the full pentad and may initially even emphasize other signs or symptoms.

It is becoming increasingly clear that the symptom spectrum of narcolepsy is much more extensive, including several symptoms that are not directly related to sleep such as psychiatric symptoms or obesity. ${ }^{3,4}$ Unfamiliarity with this broad clinical presentation of narcolepsy hampers the already challenging diagnostic process, and may especially preclude the early recognition of the disorder, with detrimental effects to patients.

Whilst narcolepsy has traditionally been thought of as a disease of early adulthood, at least one-third of the cases start before the age of fifteen. ${ }^{5}$ In early childhood, the clinical picture can be markedly different compared to adults, with an abrupt debut with sudden weight gain, prolonged night-time sleep, and an acute
Correspondence: Sebastiaan Overeem Sleep Medicine Center Kempenhaeghe, Sterkselseweg 65, Heeze, VE, 559I, the Netherlands

Tel +3I 402279400

$\mathrm{Fax}+31402279399$

Email s.overeem@tue.nl 
movement disorder. ${ }^{6}$ In adults as well, the clinical phenotype may change from initial presentation. Although narcolepsy was previously considered a chronic disease with a relatively stable course, recent studies point out that EDS and cataplexy symptoms could diminish over time. ${ }^{7,8}$ Importantly, the experienced symptom burden is greatly influenced by external circumstances.

Taken together, the broad variety of symptoms between but also within patients, plus the differences in expression of symptoms throughout the lifespan with a different and sometimes peculiar pediatric phenotype, makes it complex to identify and diagnose patients with narcolepsy, increasing the risk of the condition being unrecognized, misinterpreted or misdiagnosed.

Narcolepsy has a profound effect on wellbeing, both on an individual and a societal level. Accurate and timely diagnosis followed by appropriate treatment could help to limit these consequences. A delay in diagnosis can have significant effects on the burden of the disease. Not only efficacious treatment options will be delayed, but misinterpreted or mislabeled signs and symptoms could result in negative responses from the environment of patients adding to the social stigma.

In this review, we provide a detailed overview of the broad and dynamic symptom spectrum of narcolepsy, with a specific focus on the broad variety of symptoms and comorbidities. The complex and sometimes even paradoxical childhood phenotype will receive special attention. The overarching goal is to help not only sleep specialists, but general practitioners, pediatricians, and other caregivers with early recognition and prompt diagnosis.

\section{Symptom Debut and Diagnostic Delay}

Narcolepsy symptoms most often have a debut in adolescence, with a peak at around fifteen years of age and a small second peak of onset around age thirty-five. ${ }^{5}$ However, childhood narcolepsy might be more frequent than previously thought, given the discrepancy between the number of patients receiving a diagnosis before the age of fifteen and the number of patients who report symptom onset prior to that age. ${ }^{9,10}$ A significant diagnostic delay has been consistently found in the narcolepsy literature, independent of geographical region. ${ }^{10}$ The mean latency between symptom onset and a diagnosis of narcolepsy varies between eight years up to even nineteen years. ${ }^{9,11-14}$ Some less severely affected patients may never learn that they are suffering from narcolepsy at all.

Cataplexy as a presenting symptom is associated with a shorter diagnostic interval in several studies. ${ }^{14,15}$ Pediatric onset of symptoms increased the odds for a delayed diagnosis in some studies ${ }^{16}$ but Luca et al found a young age of onset of symptoms was associated with a shorter delay of diagnosis. ${ }^{15}$ Possibly, increased awareness of pediatric narcolepsy in the last decade is at the root of this. Media attention could be of influence in the diagnostic delay, as was shown in the H1N1 flu pandemic. The association between AS03-adjuvanted H1N1 vaccines and the onset of narcolepsy received very wide media coverage, leading to a shorter diagnostic gap. ${ }^{17}$

\section{Screening for the Narcolepsy Symptom Spectrum}

The diagnostic criteria for narcolepsy as outlined in the International Classification of Sleep Disorders (ICSD-3) ${ }^{18}$ are not designed for screening and early recognition, hence stressing the importance of symptom awareness. A limited number of tools have been developed to aid in this challenge. Questionnaires such as the Ullanlinna Narcolepsy Scale (UNS) and the Swiss Narcolepsy Scale (SNS) have acceptable psychometric properties. Yet, since they only focus on EDS and cataplexy, other symptoms that could indicate the presence of narcolepsy are ignored. ${ }^{19-21}$ The Narcolepsy Severity Scale (NSS) expands its scope to the pentad of narcolepsy symptoms and has adequate psychometric properties with a good item convergent validity, reliability, and adequate properties for both clinic and research utility. ${ }^{22,23}$ However, despite these positive characteristics, the NSS is not able to chart the colorful palette of narcolepsy symptoms.

The timely recognition of -possible- narcolepsy therefore relies primarily on the detection of early symptoms by healthcare providers. Knowledge of the broad variety of symptoms and the variation in presentation between patients, partly depending on age, is therefore of paramount importance. Recently, we developed the Narcolepsy Monitor, a mobile app to monitor the presence and experienced burden of a broad spectrum of narcolepsy symptoms over time. The core concept is based on a visual representation of the perceived burden of a variety of symptoms. ${ }^{24}$ In Figure 1, the reported presence and burden of symptoms is shown in a population sample of more than 700 self-reported narcolepsy patients. These data 
not present

apresent

SYMPTOMS - PRESENCE AT BASELINE

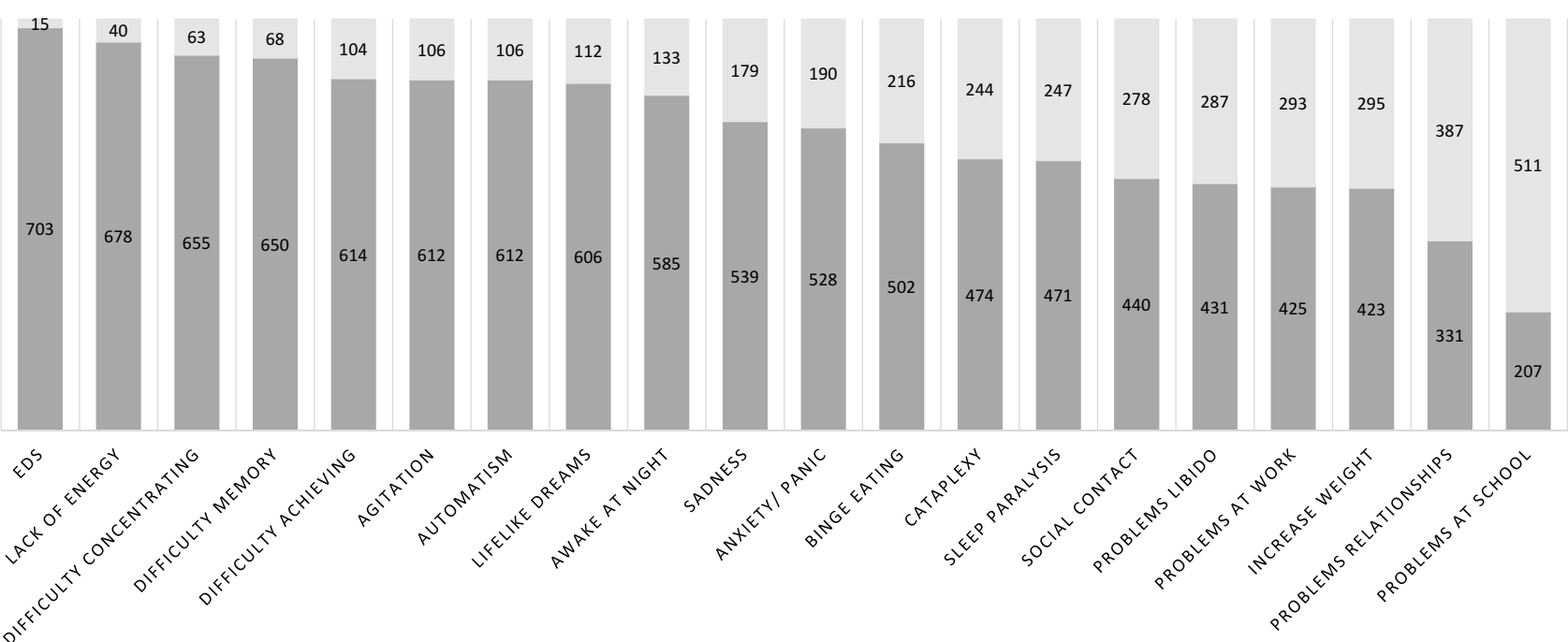

Figure I Reported presence of symptoms in narcolepsy, using the Narcolepsy Monitor, a mobile app to rate symptom presence and burden. ${ }^{24}$ Data are shown from a population sample of 718 subjects between 18 and 70 years of age, who scored >10 on the Ullanlinna Narcolepsy Scale (UNS) and reported to be formally diagnosed with narcolepsy. Median age 32 years, median UNS score 21. Symptoms are shown in order from highest to lowest presence.

strikingly show that the narcolepsy spectrum reaches beyond the classic pentad of symptoms. Below we describe the different symptoms of narcolepsy in more detail, with emphasis on the various manifestations, variety in severity, and differential presentation in children and adults.

\section{Excessive Daytime Sleepiness and Related Phenomena}

EDS is a core symptom of narcolepsy. In essence, it refers to the inability to stay awake and alert during the major waking episodes of the day, resulting in periods of irrepressible need for sleep or unintended lapses into sleep. In ICSD-3, the term "hypersomnolence" is used. ${ }^{18}$ Although this can sometimes be surprisingly difficult, EDS should be distinguished from fatigue, which in fact can be regarded as a separate symptom often occurring in narcolepsy (see below).

EDS is usually the presenting symptom of narcolepsy both in children and adults, although this may often only be recognized later, when other symptoms prompted a formal diagnosis. When sleepiness is experienced in active conditions (eg, during a conversation or while driving a car), its pathological nature is more easily identified. However, patients experience drowsiness predominantly during passive conditions, such as sitting in a classroom or being a passenger in a vehicle, and this may sometimes be regarded as a bothersome, but "normal" phenomenon by bystanders, attributing it to sleep deprivation or 'laziness'. Daytime sleep episodes in narcolepsy are characteristically but not invariably relatively short (10-20 minutes) and are typically perceived as - temporarily - refreshing. These may all be clinical leads to distinguish narcolepsy from other disorders of hypersomnolence such as idiopathic hypersomnia. ${ }^{25}$

\section{EDS Related Phenomena}

It is not surprising that unintentional sleep attacks especially in active, unusual, or dangerous situations play a pivotal role in the diagnostic process. However, this focus may inadvertently lead to an under evaluation of perhaps equally important symptoms, which can be viewed as different manifestations of EDS. Automatic behavior could be the expression of resisting the high sleep pressure and is characterized by the continuation of activities with amnesia afterward. ${ }^{26}$ These automatic behaviors are generally related to routine activities that require little attention but may involve significant errors or risks, such as driving. Typical examples are continuing to write in unreadable scribble, or suddenly addressing a very different topic in a conversation. More striking examples are putting the dishes in the fridge or pouring coffee in the ashtray. Patients do not typically recognize these episodes as caused by sleepiness and may be ashamed to report 
them. If present, they should prompt physicians to further investigate the presence of other indicators of EDS.

Narcolepsy patients report difficulties with attention and vigilance in everyday situations, leading to impairment of performance in the waking state to be one of the most important complaints. ${ }^{16,27-29}$ Subjective reports of these cognitive complaints are difficult to capture in objective, neuropsychological tests, with different measurement tools showing varying deficits. ${ }^{27,30,31}$ Several studies using the Sustained Attention to Response Task (SART) have confirmed that vigilance in patients with EDS and specifically narcolepsy is impaired. ${ }^{28,29,31}$

\section{EDS and Related Phenomena in Children}

Although EDS is often a presenting symptom of narcolepsy in the pediatric population, symptom recognition may be challenging due to different manifestations. EDS may present with inattention, irritability, and automatic behaviors, or paradoxically with hyperactivity. Total sleep hours per day can increase, with earlier sleep times and later wake up times with major difficulties in the morning awakening. The need for (age-inappropriate) naps may return. ${ }^{32}$ EDS can easily be overlooked or mislabeled as laziness or inattention or lead to a misdiagnosis of behavioral conditions such as Attention Deficit Hyperactivity Disorder (ADHD). ${ }^{33}$

\section{Cataplexy}

Cataplexy refers to an intermittent, brief occurrence of muscle paralysis, either localized in certain muscle groups or leading to a generalized atonia resulting in falls. A typical attack has a stammering start of weakness, usually in the neck or facial muscles, and an associated uncontrolled, irregular tremor of the head with facial twitching. Within a few seconds, the muscle weakness spreads craniocaudal to a generalized paralysis if the attack is complete. Partial attacks affect only a distinct part of the body and can be difficult to recognize. In a group with 109 patients with narcolepsy type 1, almost $30 \%$ of patients reported only partial attacks compared with $24 \%$ only complete attacks. ${ }^{34}$ Slight drooping of the head, dropping of an item from the hand, or slurred speech are examples of visible manifestations of a partial cataplectic event. ${ }^{35}$ It typically occurs in situations in which mirth is present, such as laughing, chuckling, or telling a joke. However, negative emotions like anger or fear could also trigger cataplexy. ${ }^{36,37}$ As a feeling of being weak with laughing may occur in healthy people, the presence of other triggers for cataplexy should be actively inquired about, as this makes the diagnosis much more specific. ${ }^{34}$ The frequency of episodes varies from less than one per year up to more than 20 per day, with more rare occurrences being much more difficult to pick up by caregivers. Duration is typically short in the order of several seconds, but more severe or consecutive attacks may last up to a few minutes. ${ }^{38}$

In general, cataplexy occurs close to the start of EDS. Since it is pathognomonic for narcolepsy, correct identification can be crucial in the diagnostic process. However, cataplexy is rarely observed in the clinical environment and must be diagnosed by a thorough clinical history. Recognition of cataplexy by patients themselves can be poor with explanations such as "just being clumsy" to account for certain behavior. Other patients might unknowingly have developed avoidance techniques to "mute" emotional experiences. Observation of video-documented cataplexy attacks could be used to further enhance the clinical diagnostic trajectory. ${ }^{39}$

Cataplexy episodes may be confused with syncope, ${ }^{40}$ transient ischemic attacks, ${ }^{41}$ falls from neuromuscular disorders, $^{42}$ epileptic seizures, ${ }^{43}$ or psychiatric disorders. ${ }^{44}$ Pseudo cataplectic attacks in patients with a valid diagnosis of narcolepsy, as in attacks that are not consistent with cataplexy, can occur and can be viewed as a comorbid somatoform disorder. ${ }^{44-46}$ Key features of cataplexy are the typical course of the attack, mostly triggered by positive emotions, accompanied by the progression of weakness with positive motor phenomena such as facial jerks, intact awareness, the absence of speech arrest, and an abrupt recurrence of muscle tone after the attack. $^{36,45}$

\section{Cataplexy in Children}

In children, cataplexy may look much different, particularly directly after disease onset (see Table 1). Pediatric cataplexy often presents as striking hypotonia especially in the face, in combination with a complex movement disorder. Limb and trunk muscles are less involved and a prominent facial involvement with facial hypotonia, bilateral ptosis, mouth opening, and tongue protrusion is evident. A clear emotional trigger may be difficult to identify sometimes, with seemingly spontaneous attacks. $^{39,48}$ Childhood episodes are often partial but prolonged. This typical and spontaneous childhood cataplexy gradually disappears, morphing into the classical "adult" form, with shorter, more localized muscle weakness linked 
Table I Adult versus Pediatric Cataplexy

\begin{tabular}{|c|c|c|}
\hline & Adults & Children \\
\hline $\begin{array}{l}\text { Typical features close } \\
\text { to disease onset } \\
6,47\end{array}$ & Not well described & $\begin{array}{l}\text { Complex movement disorder consisting of 'negative' (hypotonia) and } \\
\text { 'active' motor disturbances (ranging from peri-oral movements to } \\
\text { dyskinetic-dystonic movements or stereotypies) }\end{array}$ \\
\hline $\begin{array}{l}\text { Clinical } \\
\text { presentation }^{39,48}\end{array}$ & $\begin{array}{l}\text { Facial twitching, but not as pronounced as in } \\
\text { children } \\
\text { Relatively prominent involvement of the jaw, } \\
\text { neck, or lower limbs }\end{array}$ & $\begin{array}{l}\text { Cataplectic facies with a loss of facial muscle tone resulting in facial } \\
\text { droop, grimacing, tongue protrusion, eyelid weakness causing ptosis, } \\
\text { head rolling, and a lack of head control. } \\
\text { 'Puppet' or chorea-like whole body movements }\end{array}$ \\
\hline Duration $^{35}$ & $<2$ seconds up till $\mathrm{I}-2$ minutes & Prolonged duration \\
\hline Trigger $^{35-37}$ & $\begin{array}{l}\text { Mirth; as in laughing, telling a joke } \\
\text { Surprise; meeting an acquaintance } \\
\text { 'Anticipation'; eg having a great chance to score } \\
\text { a point in sports }\end{array}$ & $\begin{array}{l}\text { Watching funny movies } \\
\text { Being reprimanded by the parents } \\
\text { During sports activities, or tasks demanding high concentration } \\
\text { (gaming, writing) } \\
\text { While eating } \\
\text { Evident triggers may be absent, with seemingly spontaneous attacks }\end{array}$ \\
\hline Development ${ }^{7,8,49}$ & $\begin{array}{l}\text { Possible decrease of the frequency of cataplectic } \\
\text { attacks and remission of cataplectic severity } \\
\text { But; may be caused by avoidance of triggers }\end{array}$ & $\begin{array}{l}\text { Evolution of the pediatric phenotype into the classical adult } \\
\text { phenotype in the months after the debut }\end{array}$ \\
\hline
\end{tabular}

with clear emotional stimulation. ${ }^{6,47,48}$ The pediatric cataplexy phenotype may easily be misinterpreted when unrecognized, leading to a workup for neuromuscular or choreatic disorders, with a delay in diagnosis.

\section{Fragmented Nighttime Sleep}

In essence, narcolepsy is a disorder of sleep-wake instability. Many patients experience a highly fragmented nighttime sleep, reporting frequent nocturnal awakenings and overall poor sleep quality. ${ }^{50}$ We consider the complaint of fragmented nighttime sleep as a separate symptom, as it does not seem to be fully explained by comorbid sleep disorders, which may of course further disrupt nocturnal sleep and are discussed separately.

The sleep pattern at polysomnography (PSG) shows an increased frequency of sleep stage shifts besides multiple, often short awakenings. ${ }^{15,51-53}$ Importantly, sleep fragmentation does not seem to account for daytime symptoms. ${ }^{54,55}$ Given the frequent occurrence, the presentation of nocturnal sleep fragmentation in combination with daytime sleepiness should prompt suspicion of narcolepsy, even though insomnia is often considered first.

\section{Fragmented Nighttime Sleep in Children} Although studies in pediatric populations are limited, fragmented nighttime sleep is also a distinct sleep pathology found in young narcolepsy patients. ${ }^{52}$ A recent survey study by Ingram, showed fragmented nighttime sleep in fact to be the second most common and problematic complaint in narcolepsy as rated by young patients (twenty two years or younger) and their parents. ${ }^{56}$ In children, fragmented nighttime sleep may even be more underestimated given the tendency to contribute an unstable nighttime sleep to common behavioral sleep problems of childhood.

\section{Co-Morbid Sleep Disturbances}

Several nocturnal sleep disorders can be present in patients with narcolepsy, with a higher prevalence than the general population. These are listed in Table 2. In several instances, it is unclear if these disorders should be viewed as part of the primary narcolepsy, or secondary comorbidity. For example, it is under debate whether rapid eye movement (REM) sleep behavior disorder (RBD) in narcolepsy must be viewed as an intrinsic feature, linked to the hypocretin deficiency, or as an associated feature, with the underlying mechanisms still unknown. ${ }^{57}$ The same holds for other parasomnias. The increased frequency of sleep-related breathing disorders in narcolepsy may be associated with an increase in body weight, but might also be related to diagnostic bias in the light of the high general prevalence of these disorders. In any case, the presence of nighttime sleep disorders can lead to misattributing narcolepsy symptoms to these comorbid sleep disorders, hence masking 
Table 2 Common Co-Morbid Sleep Disturbances in Narcolepsy Patients

\begin{tabular}{|c|c|}
\hline Comorbid Sleep Disturbances & Comments \\
\hline $\begin{array}{l}\text { REM sleep without atonia (RWA) and REM } \\
\text { Behavior Disorder (RBD) }\end{array}$ & $\begin{array}{l}\text { RWA and RBD are both more prevalent in narcolepsy compared with healthy controls. In } \\
\text { narcolepsy, the movements are more gentle, simple and calm rather than complex and } \\
\text { sometimes fierce as seen in idiopathic RBD. Contrary, pediatric narcolepsy type I patients can } \\
\text { experience quite severe motor dyscontrol. }\end{array}$ \\
\hline Sleep Disordered Breathing (SDB) ${ }^{61}$ & $\begin{array}{l}\text { Overlap of EDS as a core symptom of both narcolepsy as SDB poses diagnostic and treatment } \\
\text { challenges. The coexistence of SDB in patients with narcolepsy may result in narcolepsy being } \\
\text { overlooked. In young narcoleptic patients, SDB seems to be a rare condition and if present, very } \\
\text { mild. }\end{array}$ \\
\hline Restless Legs Syndrome (RLS) ${ }^{62-64}$ & $\begin{array}{l}\text { RLS in narcolepsy type I shows a higher prevalence compared to the general population. } \\
\text { However, the picture is often milder, and with a more equal sex distribution. Further, RLS in } \\
\text { narcolepsy type I is not associated with low ferritin levels as in idiopathic RLS, which may } \\
\text { suggest differences in pathophysiology. RLS is also seen in children with narcolepsy with } \\
\text { prevalence rates around } 20 \% \text {. }\end{array}$ \\
\hline Sleep-related eating disorder (SRED) ${ }^{65}$ & $\begin{array}{l}\text { SRED is a parasomnia characterized by recurrent episodes of eating at the transition from wake } \\
\text { to sleep. SRED typically occurs as a primary parasomnia, and although not specific for } \\
\text { narcolepsy, it is suggested to be highly prevalent in narcolepsy type I. }\end{array}$ \\
\hline Other parasomnia's 66,67 & $\begin{array}{l}\text { Studies are scarce, but, especially in the pediatric population, the presence of parasomnias such } \\
\text { as night terrors or nightmares can overshadow the presence of narcolepsy symptoms such as } \\
\text { sleep-related hallucinations or sleep paralysis. Lucid dreaming is more common in patients with } \\
\text { narcolepsy compared to the general population. }\end{array}$ \\
\hline
\end{tabular}

the narcolepsy and delaying its diagnosis. This underscores again the importance of a broad diagnostic view, and a complete sleep history in all patients with suspected sleep disorders.

\section{Sleep-Related Hallucinations}

Narcolepsy patients often experience hypnagogic or hypnopompic hallucinations; vivid hallucinatory experiences when falling asleep or waking up respectively. These can also occur during daytime naps. Hypnagogic hallucinations are not exclusively experienced by patients with narcolepsy, they may occur in the general population and are more prevalent in the context of psychiatric disorders. ${ }^{68}$ The presence of sleep-related hallucinations in narcolepsy patients can increase the risk of misdiagnosis due to the resemblance with schizophrenia and other psychotic disorders, and foster a further diagnostic delay. ${ }^{69}$ However, the pattern of the hallucinatory experiences may provide important diagnostic clues and should be carefully evaluated. Phenotypically, the hallucinations in narcolepsy are reported to be multisensory and "holistic", with prominent visual sensations, often mixed with the actual environment, combined with auditory and even tactile sensations.

\section{Sleep-Related Hallucinations in Children}

In children, differentiating between reality and a hallucination can be especially challenging. Shame or fear may even further impede the description of the experience. On the other hand, hallucinations in children with narcolepsy might, in contrast to the hallucinations in adult patients, be less frightening and involve simple forms (such as colored circles, images of animals, or people). ${ }^{70}$ Sleep-related hallucinations in the pediatric population may be easily confused with other parasomnias frequently occurring in childhood, such as nightmares, sleep terrors, or the Alice in Wonderland syndrome. Time of occurrence, and recollection the next morning are differentiating features.

\section{Sleep Paralysis}

Sleep paralysis describes the inability to speak or move during the transitions between sleep and wake. Especially the feeling of not being able to breathe or feelings of heaviness on the chest is typical for sleep paralysis and can be very frightening. The paralysis may last from several seconds up to minutes, but patients seem to have difficulty in reporting the duration of an attack of sleep paralysis. Once one muscle can be moved (some people 
report focusing on a thumb or little finger), the attack is typically resolved quickly. Sleep paralysis is not exclusive in narcolepsy; however, a frequently recurring pattern is rather typical, and should always prompt further investigation. $^{71}$

\section{Sleep Paralysis in Children}

Sleep paralysis seems to be less frequently reported by children compared to adults. Its occurrence gradually increases with age. ${ }^{72,73}$ Similar to hallucinations, verbalizing the inability to move and distinguish the transitional conditions between REM sleep and wakefulness can be quite difficult and stressful for young narcolepsy patients and might lead to underestimation. Anxiety when going to bed could be a potential signal for the presence of sleep paralysis and warrants further exploration.

\section{Weight Gain and Obesity}

A high prevalence of overweight, as well as obesity, has been reported for both children and adults with hypocretindeficient narcolepsy. Rates vary from $30 \%$ to $60 \%$ having a body mass index (BMI) above 25 , and a BMI $>30$ is twice as common as in controls. ${ }^{74-76}$ As a contributing factor, some form of eating "dysregulation" is reported by many patients, including "carbo craving", especially for sweets. Importantly, body weight may increase quickly and prominently at disease onset and can be rather dramatic especially in children. Therefore, rapid unexplained weight gain in combination with daytime sleepiness should raise a strong suspicion of narcolepsy.

\section{Precocious Puberty}

Precocious puberty, as in a too early onset of puberty stages, occurs in $17 \%$ of the young narcoleptic patients, compared to $1.9 \%$ in an obese control population. ${ }^{75}$ Recognizing precocious puberty as part of the narcolepsy spectrum when analyzing early onset pubertal signs might add to early detection.

\section{Fatigue}

Severe fatigue is a frequently reported symptom in narcolepsy, independently of EDS. ${ }^{16}$ Fatigue refers to a subjective experience of mental or physical exhaustion, with a strong desire to rest, which does not disappear after a period of sleep. Differentiation with sleepiness can be difficult. An important clue is the fact that in case of sleepiness, patients typically want to remain physically active to suppress it, while in fatigue, there is a tendency to rest. In our clinical experience, EDS tends to decrease significantly on stimulant use, whereas fatigue is much less responsive to stimulant drugs. ${ }^{77}$ Autonomic dysfunction has been described in narcolepsy in several studies, and has been put forward as a possible mechanism leading to fatigue as well. ${ }^{78-81}$ Importantly, a presenting complaint of fatigue should always prompt to probe whether sleepiness is present, and a prominent fatigue complaint does not rule out narcolepsy.

\section{Fatigue in Children}

In children, making the distinction between EDS and fatigue is often even more challenging. However, studies have shown that fatigue is also a highly prevalent complaint in pediatric narcolepsy. ${ }^{82}$ In our clinical opinion, fatigue is a persistent symptom in pediatric narcolepsy, very often related to a burden of school performance. When fatigue is present in narcoleptic children it increases the risk of depressive and ADHD symptoms and the frequency of cataplexy attacks. ${ }^{33,34,83}$

\section{Psychiatric Symptoms}

Many studies report strikingly high comorbidity of psychiatric symptoms in narcolepsy, which is thought to be an important factor in the delay in diagnosis (see Table 3 for an overview). ${ }^{3,84,85}$ Mood symptoms and disorders often occur, and an increased risk of suicide has been reported. ${ }^{3,86}$ Moreover, anxiety disorders seem particularly common, especially social phobias and panic attacks. ${ }^{87}$ The craving for food can be so prominent that it classifies as an eating disorder symptom. Almost a quarter of narcolepsy patients fulfill the diagnostic criteria for an eating disorder, most notably binge eating disorder. ${ }^{88,89}$

Behavioral problems, problems in social functioning, and ADHD are very common in young narcolepsy patients. $^{33,90}$ In fact, a diagnosis of ADHD, mood, or anxiety disorders often precedes the diagnosis of narcolepsy. ${ }^{12,91,92}$ Given the overlap in pharmaceutical treatment, this could mask narcolepsy symptoms and further enhance the risk of a delayed diagnosis.

The complex relationship between narcolepsy and psychiatric symptomatology can result in a significant delay in diagnosis and treatment either for the psychiatric condition or the narcolepsy. The shared common features create challenges in making the correct diagnosis, emphasizing the need for detailed knowledge of the clinical expression of psychiatric symptoms within the symptom spectrum of narcolepsy. 
Table 3 Common Psychiatric Symptoms or Disorders in Narcolepsy

\begin{tabular}{|c|c|}
\hline Symptom or Disorder & Comments \\
\hline Anxiety $3,12,42,85,87,93$ & $\begin{array}{l}\text { Studies show a striking presence of anxiety symptoms or even disorders, with generalized anxiety being the } \\
\text { most studied. The unpredictability and uncontrollability of symptoms such as EDS or cataplexy can make people } \\
\text { develop social anxieties and specific phobias may arise from the frightening character hallucinations can have. } \\
\text { Diagnosis of an anxiety disorder often precedes the diagnosis of narcolepsy. It is suggested that the undiagnosed } \\
\text { symptoms of narcolepsy cause high levels of anxiety which might even further delay diagnosis. }\end{array}$ \\
\hline Mood disorders $3,|2,85,86,9|-96$ & $\begin{array}{l}\text { Mood symptoms or disorders are frequently reported by narcolepsy patients. Studies have indicated that } 30 \\
50 \% \text { of patients were diagnosed with a mood disorder before the diagnosis of narcolepsy. Given the overlap in } \\
\text { symptoms and treatment, a diagnosis of narcolepsy could be easily overseen. }\end{array}$ \\
\hline $\mathrm{ADHD}^{33,42,94,97-99}$ & $\begin{array}{l}\text { ADHD is a frequent comorbidity in narcolepsy, both in children as in adults. Pediatric narcolepsy is } \\
\text { characterized by hyperactivity, irritability, emotional dysregulation, aggression, distractibility, impulsiveness, and } \\
\text { restlessness. These behaviors may be a reflection of the child's external response to an internal feeling of } \\
\text { sleepiness or an attempt to resist it by engaging in self-stimulatory behavior. This clear overlap between } \\
\text { narcolepsy and ADHD symptomatology increases the risk of misdiagnosis. However, also in the adult } \\
\text { population, an overlap of symptoms between narcolepsy and ADHD is present, which could lead to diagnostic } \\
\text { confusion. }\end{array}$ \\
\hline $\begin{array}{l}\text { Autism/ disrupted social } \\
\text { interaction }^{90,100,101}\end{array}$ & $\begin{array}{l}\text { Studies on social functioning or the occurrence of autism symptoms are scarce. However, there is growing } \\
\text { evidence for impaired social functioning in children with narcolepsy. Some studies describe a so-called } \\
\text { 'narcoleptic personality', which includes introversion, impaired affectivity modulation, irritability, and poor } \\
\text { attention and overlaps with the clinical features of an autism spectrum disorder. }\end{array}$ \\
\hline Eating disorders ${ }^{88,89}$ & $\begin{array}{l}\text { Changes in eating patterns with 'carbo craving', binge eating tendency, and nocturnal eating are very prevalent } \\
\text { in narcolepsy. In one study, it was even found that almost } 25 \% \text { of narcolepsy type I patients fulfilled the criteria } \\
\text { for a clinical eating disorder. }\end{array}$ \\
\hline Suicidality ${ }^{85,86,102-104}$ & $\begin{array}{l}\text { Several studies show an increased risk of suicide in patients with narcolepsy, but the underlying relationship is } \\
\text { complex. Sleep disturbances and EDS have been shown to be risk factors for suicide and lower levels of } \\
\text { cerebrospinal fluid (CSF) hypocretin have been observed in depressed patients with suicidal behavior. It should } \\
\text { be noted that suicidal ideations have been reported as a medication side effect. }\end{array}$ \\
\hline Chronic pain ${ }^{105,106}$ & $\begin{array}{l}\text { Chronic pain is significantly more common and disabling in patients with narcolepsy type I and narcolepsy type } \\
\text { 2. Although it is suggested the hypothalamic dysfunction plays a role in the high prevalence of chronic pain in } \\
\text { narcolepsy, depression could also possibly influence pain perception. }\end{array}$ \\
\hline
\end{tabular}

\section{Cognitive Disturbances}

Patients with narcolepsy often complain about difficulties with learning, concentration, and memory. Different study methods and procedures, a great variety of tests applied and the lack of consensus about definitions, make it difficult to draw conclusions about the presence of objective cognitive impairments. With this in mind, the most pronounced evidence was found for impairment of alertness and sustained attention/vigilance. ${ }^{28,107,108}$ Some studies suggest that the subjectively experienced difficulties correlate more with EDS and depression compared to objective test results. ${ }^{27}$

In children, studies on cognitive functioning have focused on the intelligence quotient (IQ). Children with narcolepsy have total IQ scores within the average range but are more likely to yield significant uneven cognitive profiles when comparing verbal to nonverbal (performal) subscale scores. ${ }^{109-111} \mathrm{~A}$ decline in IQ over time is not to be expected in narcolepsy, as was shown by a study of Janssens et al, who showed that recently diagnosed narcolepsy type 1 patients improved significantly on total IQ score after one year of treatment. ${ }^{112}$ This also suggests, that although children with narcolepsy still perform within the average range, their cognitive abilities are suppressed by EDS, which can be relieved with proper treatment.

\section{Discussion and Perspectives}

The chronic course of narcolepsy, its early onset, severe symptoms, associated comorbidities, and unpredictable, often uncontrollable character, all add up to the great burden it poses on the lives of patients. The persisting diagnostic delay is an important problem as it leads to misinterpretation (and therefore stigmatization), 
misdiagnosis, inappropriate medication exposure, and delayed treatment. Even though there seems to be a trend over time toward a shorter diagnostic delay, it remains unacceptably long. Increased research and media attention has led to a boost of awareness, but a striking gap in knowledge persists, even in specialized sleep physicians. ${ }^{113}$ For early recognition, the most important "tool" remains a thorough knowledge of the symptom spectrum of narcolepsy, which is significantly broader than often recognized. Moreover, symptom presentation varies with age and time from disease onset. We have provided a clinically focused discussion of these aspects, to support care-givers in the early recognition and diagnosis of narcolepsy.

A substantial economic burden has been described to result from narcolepsy, including harming patients' educational achievements, income, or ability to work. ${ }^{114,115}$ Interestingly, patients diagnosed before the age of thirty show better outcomes in terms of less unemployment and better health perception compared to those diagnosed after the age of thirty, suggesting that early recognition promotes these aspects. ${ }^{11}$ Utilization of health care and average per narcolepsy patient costs are significantly higher when compared with a control population, both in children and adults. ${ }^{114,116}$ Albeit no information is available about the effect of early diagnosis on health care utilization or costs, a rapid diagnosis will shorten the diagnostic process and abate the number of visits with numerous specialists.

\section{The Complexity of Differential Diagnosis}

Even the primary core symptoms of narcolepsy, EDS and cataplexy, are not fully specific for the disease, and/or mimics may lead to other diagnostic conclusions. EDS can occur in other disorders such as chronic sleep deprivation, shift work, psychiatric diseases, or secondary to nocturnal sleep disorders like sleep-disordered breathing. Cataplexy can be partial and very subtle and therefore can go unrecognized for long periods of time. Also, cataplexy attacks (often with atypical characteristics) can occur in patients with neurogenetic syndromes such as Prader-Willi syndrome or Niemann-Pick disease type $\mathrm{C}$, and in patients with brain lesions or psychiatric diseases. ${ }^{117}$ Cataplexylike episodes can present in the general population ("weak with laughter") and pseudocataplexy has been described in both patients with and without narcolepsy.

Given these various manifestations and interpretations of core symptoms of narcolepsy and the possibility of the presence of co-morbidities, medical and psychiatric care may be sought for alternative concerns, including deteriorating school performance, the worry of a substance abuse disorder, family strain, and reduced academic or social participation. Pediatricians are challenged to accurately identify the somewhat atypical features of cataplexy and EDS in children. Other features of narcolepsy in childhood may be overlooked, misdiagnosed (ADHD), or considered typical for adolescence, as fatigue and sleep deprivation is very common at this age. Sleep fragmentation, nocturnal awakenings, and poor sleep efficiency could be interpreted as insomnia of sleep-disordered breathing. The combination of rapid weight gain and EDS could also prompt a clinically narrowed focus on sleep-disordered breathing conditions. Indeed, a first consultation with a pulmonologist was shown to be associated with a longer time to diagnosis in narcolepsy. ${ }^{118}$ Various psychiatric diseases and their pharmacological treatment can lead up to EDS; however, EDS due to narcolepsy can also lead to an increase in stress and an increase of developing psychiatric conditions. The initiation of treatment with stimulants for suspected ADHD can mask the sleepiness of narcolepsy. The broad variety of manifestations of narcoleptic symptoms, therefore, require a consequent orchestrated cooperation among different specialists at the diagnostic phase, but also afterward, as an initial diagnosis other than narcolepsy may turn out to be mistaken.

\section{Early Recognition: Implications for Treatment}

Early recognition and diagnosis of narcolepsy could be significant for certain treatment possibilities. Although under debate, autoimmunity is believed to be responsible for the hypocretin neuron loss. Some case reports and uncontrolled small series suggest that immunomodulatory treatment, such as intravenous immunoglobulin, is able to ameliorate narcolepsy symptoms and influence hypocretin status (see Giannoccaro, 2020 for an overview). ${ }^{119}$ Based on the assumption that immunomodulatory treatment could prevent neuronal death, it should be administered as close to disease onset as possible. However, the presence of cataplexy already indicates the loss of the majority of hypocretinergic cells. ${ }^{120}$ Recognition of narcolepsy even before cataplexy onset is therefore crucial in order to modify the course of the pathological process. The emerging evidence of T-cell activation in the blood and CSF of narcolepsy type 1 patients in a very early stage of the disease might become useful in early 
recognition as well as timing of immunomodulatory treatment. $^{121,122}$

\section{Increasing Awareness}

There is a need for educational programs to increase awareness regarding narcolepsy symptoms, co-morbidities, and the resulting effects on quality of life. Since narcolepsy symptoms can mimic several other, more known, disorders such as ADHD or sleep disordered breathing, such programs should not only target sleep specialists and neurologists, but a wider range of health care providers, especially pediatricians, psychiatrists, and pulmonologists. Initiatives to increase awareness should also address teachers, school counselors, psychologists, and parents. In Italy, a trend toward a shorter diagnostic delay was shown since the initiation of various media campaigns to increase awareness by the Italian patient association (Associazione Italiana Narcolettici e Ipersonni) since the year $2000 .^{32}$

\section{Future Perspectives}

Technological advances may provide new opportunities to recognize, assess or monitor narcolepsy symptoms. For example, mobile apps could provide ways to capture a broad symptom spectrum without costing much time to the user. This will also allow the study of temporal dynamics of symptoms and their interaction. ${ }^{24}$ Such approaches may be more sensitive and likely also more clinically relevant than current questionnaires, which necessarily focus on a relatively small part of the clinical picture of narcolepsy. Big data with artificial intelligencebased analysis may identify new phenotypes as it learns to recognize clinical features that may not be detected in a standard clinical interview. ${ }^{123}$

In summary, narcolepsy should be included in the differential diagnosis of all patients with excessive daytime sleepiness, not only in severe cases with unwanted lapses into sleep, but also when difficulties with attention and vigilance are the most prominent complaint. Professionals should be aware that different causes of EDS can co-exist. The symptom spectrum of narcolepsy is much broader than the classical pentad. It also varies with time after disease onset, and markedly differs between children and adults. Lesser known symptoms of narcolepsy seem to be very important to improve early recognition, with rapid weight gain around disease onset as an important example.

\section{Abbreviations}

EDS, excessive daytime sleepiness; ICSD-3, International Classification of Sleep Disorders, $3^{\text {rd }}$ edition; CSF, cerebrospinal fluid; UNS, Ullanlinna Narcolepsy Scale; SNS, Swiss Narcolepsy Scale; NSS, Narcolepsy Severity Scale; SART, Sustained Attention Response Task; ADHD, Attention Deficit Hyperactivity Disorder; BMI, body mass index; PSG, polysomnography; REM, rapid eye movement,; RWA, REM sleep without atonia; RBD, REM sleep behavior disorder; SDB, Sleep disordered breathing; RLS, restless legs syndrome; SRED, sleep related eating disorder; IQ, intelligence quotient.

\section{Acknowledgments}

This work was performed within the IMPULS framework of the Eindhoven MedTech Innovation Center (e/MTIC, a collaboration between Sleep Medicine Centre Kempenhaeghe, Eindhoven University of Technology, and Philips Research), co-financed with a PPS-supplement for research and innovation from the Dutch Ministry of Economic Affairs and Climate.

\section{Disclosure}

Dr Sigrid Pillen reports personal fees from Consultant for Conect4Children, outside the submitted work.

Prof. Dr. Sebastiaan Overeem reports grants from UCB Pharma, during the conduct of the study; and consulting, paid to institution from Bioprojet, Takeda and Jazz Pharmaceuticals, outside the submitted work. The authors report no other potential conflicts of interest for this work.

\section{References}

1. Longstreth WT, Koepsell TD, Ton TG, Hendrickson AF, van Belle G. The epidemiology of narcolepsy. 2007;30(1):14.

2. Peyron C, Faraco J, Rogers W, et al. A mutation in a case of early onset narcolepsy and a generalized absence of hypocretin peptides in human narcoleptic brains. Nat Med. 2000;6(9):991-997. doi:10.1038/ 79690

3. Ruoff CM, Reaven NL, Funk SE, et al. High rates of psychiatric comorbidity in narcolepsy: findings from the Burden of Narcolepsy Disease (BOND) study of 9,312 patients in the United States. $J$ Clin Psychiatry. 2017;78(2):171-176. doi:10.4088/JCP.15m10262

4. Schuld A, Hebebrand J, Geller F, Pollmächer T. Increased body-mass index in patients with narcolepsy. Lancet Lond Engl. 2000;355 (9211):1274-1275. doi:10.1016/S0140-6736(05)74704-8

5. Dauvilliers Y, Montplaisir J, Molinari N, et al. Age at onset of narcolepsy in two large populations of patients in France and Quebec. Neurology. 2001;57(11):2029-2033. doi:10.1212/ wn1.57.11.2029

6. Pizza F, Franceschini C, Peltola H, et al. Clinical and polysomnographic course of childhood narcolepsy with cataplexy. Brain J Neurol. 2013;136(12):3787-3795. doi:10.1093/brain/awt277 
7. Almeneessier AS, Alballa NS, Alsalman BH, Aleissi S, Olaish AH, BaHammam AS. A 10-year longitudinal observational study of cataplexy in a cohort of narcolepsy type 1 patients. Nat Sci Sleep. 2019;11:231-239. doi:10.2147/NSS S229105

8. Büchele F, Baumann CR, Poryazova R, Werth E, Valko PO. Remitting narcolepsy? Longitudinal observations in a hypocretin-deficient cohort. Sleep. 2018;41:9. doi:10.1093/sleep/ zsy118

9. Thorpy M, Cronin S, Temple H. Age of onset and time to diagnosis of narcolepsy. Neurology. 1999;52:6.

10. Thorpy MJ, Krieger AC. Delayed diagnosis of narcolepsy: characterization and impact. Sleep Med. 2014;15(5):502-507. doi:10.1016/j.sleep.2014.01.015

11. Ingravallo F, Gnucci V, Pizza F, et al. The burden of narcolepsy with cataplexy: how disease history and clinical features influence socio-economic outcomes. Sleep Med. 2012;13(10):1293-1300. doi:10.1016/j.sleep.2012.08.002

12. Taddei RN, Werth E, Poryazova R, Baumann CR, Valko PO Diagnostic delay in narcolepsy type 1: combining the patients' and the doctors' perspectives. J Sleep Res. 2016;25(6):709-715. doi: $10.1111 /$ jsr. 12420

13. Frauscher B, Ehrmann L, Mitterling T, et al. Delayed diagnosis, range of severity, and multiple sleep comorbidities: a clinical and polysomnographic analysis of 100 patients of the innsbruck narcolepsy cohort. J Clin Sleep Med JCSM off Publ Am Acad Sleep Med. 2013;9(8):805-812. doi:10.5664/jcsm.2926

14. Morrish E, King MA, Smith IE, Shneerson JM. Factors associated with a delay in the diagnosis of narcolepsy. Sleep Med. 2004;5 (1):37-41. doi:10.1016/j.sleep.2003.06.002

15. Luca G, Haba-Rubio J, Dauvilliers Y, et al. Clinical, polysomnographic and genome-wide association analyses of narcolepsy with cataplexy: a European Narcolepsy Network study. J Sleep Res. 2013;22(5):482-495. doi:10.1111/jsr.12044

16. Maski K, Steinhart E, Williams D, et al. Listening to the patient voice in narcolepsy: diagnostic delay, disease burden, and treatment efficacy. J Clin Sleep Med JCSM off Publ Am Acad Sleep Med. 2017;13(3):419-425. doi:10.5664/jcsm.6494

17. Wijnans L, Lecomte $\mathrm{C}$, de Vries $\mathrm{C}$, et al. The incidence of narcolepsy in Europe: before, during, and after the influenza A (H1N1)pdm09 pandemic and vaccination campaigns. Vaccine. 2013;31(8):1246-1254. doi:10.1016/j.vaccine.2012.12.015

18. American Academy of Sleep Medicine. International Classification of Sleep Disorders - Third Edition (ICSD-3). Darien, Illinois; 2014.

19. Bargiotas P, Dietmann A, Haynes AG, et al. The Swiss Narcolepsy Scale (SNS) and its short form (sSNS) for the discrimination of narcolepsy in patients with hypersomnolence: a cohort study based on the Bern Sleep-Wake Database. $J$ Neurol. 2019;266(9):2137-2143. doi:10.1007/s00415-01909365-2

20. Hublin Null, Kaprio Null, Partinen Null, Koskenvuo Null, Heikkilä Null. The Ullanlinna Narcolepsy Scale: validation of a measure of symptoms in the narcoleptic syndrome. $J$ Sleep Res. 1994;3(1):52-59. doi:10.1111/j.1365-2869.1994.tb00104.x

21. Sturzenegger C, Baumann C, Kallweit U, Lammers G, Bassetti C. Swiss Narcolepsy Scale: a valid tool for the identification of hypocretin-1 deficient patients with narcolepsy: P937. J Sleep Res. 2014;23.

22. Dauvilliers Y, Barateau L, Lopez R, et al. Narcolepsy Severity Scale: a reliable tool assessing symptom severity and consequences. Sleep. 2020;43:6. doi:10.1093/sleep/zsaa009

23. Dauvilliers $\mathrm{Y}$, Beziat $\mathrm{S}$, Pesenti $\mathrm{C}$, et al. Measurement of narcolepsy symptoms: the Narcolepsy Severity Scale. Neurology. 2017;88(14):1358-1365. doi:10.1212/WNL.0000000000003787
24. Quaedackers L, De Wit J, Pillen S, et al. A mobile app for longterm monitoring of narcolepsy symptoms: design, development, and evaluation. JMIR MHealth UHealth. 2020;8(1):e14939. doi:10.2196/14939

25. Dauvilliers Y, Barateau L. Narcolepsy and other central hypersomnias. Contin Minneap Minn. 2017;23(4, Sleep Neurology):989-1004. doi:10.1212/CON.0000000000000492

26. Guilleminault C, Billiard M, Montplaisir J, Dement WC. Altered states of consciousness in disorders of daytime sleepiness. J Neurol Sci. 1975;26(3):377-393. doi:10.1016/0022-510x(75) 90209-9

27. Zamarian L, Högl B, Delazer M, et al. Subjective deficits of attention, cognition and depression in patients with narcolepsy. Sleep Med. 2015;16(1):45-51. doi:10.1016/j.sleep.2014.07.025

28. Fronczek R, Middelkoop HAM, van Dijk JG, Lammers GJ. Focusing on vigilance instead of sleepiness in the assessment of narcolepsy: high sensitivity of the Sustained Attention to Response Task (SART). Sleep. 2006;29(2):187-191.

29. van der Heide A, van Schie MKM, Lammers GJ, et al. Comparing treatment effect measurements in narcolepsy: the sustained attention to response task, Epworth sleepiness scale and maintenance of wakefulness test. Sleep. 2015;38(7):1051-1058. doi: $10.5665 /$ sleep. 4810

30. Ludwig B, Smith S, Heussler H. Associations between neuropsychological, neurobehavioral and emotional functioning and either narcolepsy or idiopathic hypersomnia in children and adolescents. J Clin Sleep Med JCSM off Publ Am Acad Sleep Med. 2018;14 (4):661-674. doi:10.5664/jcsm.7066

31. Naumann A, Bellebaum C, Daum I. Cognitive deficits in narcolepsy. J Sleep Res. 2006;15(3):329-338. doi:10.1111/ j.1365-2869.2006.00533.x

32. Vignatelli L, Antelmi E, Ceretelli I, et al. Red Flags for early referral of people with symptoms suggestive of narcolepsy: a report from a national multidisciplinary panel. Neurol Sci off J Ital Neurol Soc Ital Soc Clin Neurophysiol. 2019;40 (3):447-456. doi:10.1007/s10072-018-3666-x

33. Lecendreux M, Lavault S, Lopez R, et al. Attention-Deficit/ Hyperactivity Disorder (ADHD) symptoms in pediatric narcolepsy: a cross-sectional study. Sleep. 2015;38(8):1285-1295. doi: $10.5665 /$ sleep. 4910

34. Overeem S, van Nues SJ, van der Zande WL, Donjacour CE, van Mierlo P, Lammers GJ. The clinical features of cataplexy: a questionnaire study in narcolepsy patients with and without hypocretin-1 deficiency. Sleep Med. 2011;12(1):12-18. doi:10.1016/j.sleep.2010.05.010

35. Reading P. Cataplexy. Pract Neurol. 2019;19(1):21-27. doi:10.1136/practneurol-2018-002001

36. Pillen S, Pizza F, Dhondt K, Scammell TE, Cataplexy OS. Its mimics: clinical recognition and management. Curr Treat Options Neurol. 2017;19(6):23. doi:10.1007/s11940-017-0459-0

37. Krahn LE, Lymp JF, Moore WR, Slocumb N, Silber MH. Characterizing the emotions that trigger cataplexy. J Neuropsychiatry Clin Neurosci. 2005;17(1):45-50. doi:10.1176/jnp.17.1.45

38. Kornum BR, Knudsen S, Ollila HM, et al. Narcolepsy. Nat Rev Dis Primer. 2017;3:16100. doi:10.1038/nrdp.2016.100

39. Pizza F, Antelmi E, Vandi S, et al. The distinguishing motor features of cataplexy: a study from video-recorded attacks. Sleep. 2018;41:5. doi:10.1093/sleep/zsy026

40. Coleman DK, Long B, Koyfman K. Clinical Mimics: An emergency medicine-focused review of syncope mimics. J Emerg Med. 2018;54(1):81-89. doi:10.1016/j.jemermed.2017.09.012

41. Antelmi E, Pizza F, Vandi S, Plazzi G. Stereotyped episodes of aphasia and immobility: how cataplexy mimics stroke in an elderly patient. Sleep Med. 2017;36:122-124. doi:10.1016/j. sleep.2017.05.016 
42. Plazzi G, Clawges HM, Owens JA. Clinical Characteristics and burden of illness in pediatric patients with narcolepsy. Pediatr Neurol. 2018;85:21-32. doi:10.1016/j.pediatrneurol.2018.06.008

43. Yanagishita T, Ito S, Ohtani Y, et al. Two cases of childhood narcolepsy mimicking epileptic seizures in video-EEG/EMG. Brain Dev. 2018;40(10):939-942. doi:10.1016/j.braindev.20 18.05 .015

44. Meinen CN, Smith KM, Tillema J-M, Kotagal S. Pseudo status cataplecticus in narcolepsy Type 1. J Clin Sleep Med JCSM off Publ Am Acad Sleep Med. 2018;14(9):1625-1627. doi:10.5664/ jesm. 7350

45. Plazzi G, Khatami R, Serra L, Pizza F, Bassetti CL. Pseudocataplexy in narcolepsy with cataplexy. Sleep Med. 2010;11(6):591-594. doi:10.1016/j.sleep.2010.03.004

46. Pizza F, Vandi S, Poli F, et al. Narcolepsy with cataplexy mimicry: the strange case of two sisters. J Clin Sleep Med JCSM off Publ Am Acad Sleep Med. 2013;9(6):611-612. doi:10.5664/ jesm.2764

47. Plazzi G, Pizza F, Palaia V, et al. Complex movement disorders at disease onset in childhood narcolepsy with cataplexy. Brain J Neurol. 2011;134(Pt 12):3477-3489. doi:10.1093/brain/awr244

48. Serra L, Montagna P, Mignot E, Lugaresi E, Plazzi G. Cataplexy features in childhood narcolepsy. Mov Disord off J Mov Disord Soc. 2008;23(6):858-865. doi:10.1002/mds.21965

49. Parmar A, Murray BJ, Narang I. Clinical characteristics of cataplectic attacks in Type 1 narcolepsy. Curr Neurol Neurosci Rep. 2020;20(9):38. doi:10.1007/s11910-020-01057-z

50. Roth T, Dauvilliers Y, Mignot E, et al. Disrupted nighttime sleep in narcolepsy. J Clin Sleep Med JCSM off Publ Am Acad Sleep Med. 2013;9(9):955-965. doi:10.5664/jcsm.3004

51. Pizza F, Vandi S, Iloti M, et al. Nocturnal sleep dynamics identify narcolepsy Type 1. Sleep. 2015;38(8):1277-1284. doi:10.5665/ sleep. 4908

52. Maski K, Pizza F, Liu S, et al. Defining disrupted nighttime sleep and assessing its diagnostic utility for pediatric narcolepsy type 1 . Sleep. 2020;43:10. doi:10.1093/sleep/zsaa066

53. Cairns A, Bogan R. Comparison of the macro and microstructure of sleep in a sample of sleep clinic hypersomnia cases. Neurobiol Sleep Circadian Rhythms. 2019;6:62-69. doi:10.1016/j. nbscr.2019.02.001

54. Jiménez-Correa U, Haro R, Obdulia González R, VelázquezMoctezuma J. Correlations between subjective and objective features of nocturnal sleep and excessive diurnal sleepiness in patients with narcolepsy. Arq Neuropsiquiatr. 2009;67 (4):995-1000. doi:10.1590/s0004-282×2009000600006

55. Harsh J, Peszka J, Hartwig G, Mitler M. Night-time sleep and daytime sleepiness in narcolepsy. J Sleep Res. 2000;9 (3):309-316. doi:10.1046/j.1365-2869.2000.00217.x

56. Ingram DG, Jesteadt L, Crisp C, Simon SL. Perceived challenges in pediatric narcolepsy: a survey of parents, youth, and sleep physicians. J Clin Sleep Med JCSM off Publ Am Acad Sleep Med. 2021;17(1):13-22. doi:10.5664/jcsm.8774

57. Antelmi E, Pizza F, Franceschini C, Ferri R, Plazzi G. REM sleep behavior disorder in narcolepsy: a secondary form or an intrinsic feature? Sleep Med Rev. 2020;50:101254. doi:10.1016/j. smrv.2019.101254

58. Mattarozzi K, Bellucci C, Campi C, et al. Clinical, behavioural and polysomnographic correlates of cataplexy in patients with narcolepsy/cataplexy. Sleep Med. 2008;9(4):425-433. doi:10.1016/j.sleep.2007.05.006

59. Ferri R, Franceschini C, Zucconi M, et al. Searching for a marker of REM sleep behavior disorder: submentalis muscle EMG amplitude analysis during sleep in patients with narcolepsy/cataplexy. Sleep. 2008;31(10):1409-1417.
60. Antelmi E, Pizza F, Vandi S, et al. The spectrum of REM sleep-related episodes in children with type 1 narcolepsy. Brain J Neurol. 2017;140(6):1669-1679. doi:10.1093/brain/awx096

61. Filardi M, Demir N, Pizza F, et al. Prevalence and neurophysiological correlates of sleep disordered breathing in pediatric type 1 narcolepsy. Sleep Med. 2020;65:8-12. doi:10.1016/j. sleep.2019.07.004

62. Plazzi G, Ferri R, Antelmi E, et al. Restless legs syndrome is frequent in narcolepsy with cataplexy patients. Sleep. 2010;33 (5):689-694. doi:10.1093/sleep/33.5.689

63. Winstone AM, Stellitano L, Verity C, et al. Clinical features of narcolepsy in children vaccinated with AS03 adjuvanted pandemic A/H1N1 2009 influenza vaccine in England. Dev Med Child Neurol. 2014;56(11):1117-1123. doi:10.1111/dmcn.12522

64. Barateau L, Chenini S, Lotierzo M, et al. CSF and serum ferritin levels in narcolepsy type 1 comorbid with restless legs syndrome. Ann Clin Transl Neurol. 2020;7(6):924-931. doi:10.1002/ acn3.51056

65. Palaia V, Poli F, Pizza F, et al. Narcolepsy with cataplexy associated with nocturnal compulsive behaviors: a case-control study. Sleep. 2011;34(10):1365-1371. doi:10.5665/SLEEP.1280

66. Vendrame M, Havaligi N, Matadeen-Ali C, Adams R, Kothare SV. Narcolepsy in children: a single-center clinical experience. Pediatr Neurol. 2008;38(5):314-320. doi:10.1016/j. pediatrneurol.2007.12.010

67. Dodet P, Chavez M, Leu-Semenescu S, Golmard J-L AI. Lucid dreaming in narcolepsy. Sleep. 2015;38(3):487-497. doi:10.5665/ sleep. 4516

68. Ohayon MM. Prevalence of hallucinations and their pathological associations in the general population. Psychiatry Res. 2000;97 (2-3):153-164. doi:10.1016/s0165-1781(00)00227-4

69. Plazzi G, Fabbri C, Pizza F, Serretti A. Schizophrenia-like symptoms in narcolepsy type 1: shared and distinctive clinical characteristics. Neuropsychobiology. 2015;71(4):218-224. doi:10.1159/000432400

70. Nevsimalova S. The diagnosis and treatment of pediatric narcolepsy. Curr Neurol Neurosci Rep. 2014;14(8):469. doi:10.1007/s11910-014-0469-1

71. Sharpless BA. A clinician's guide to recurrent isolated sleep paralysis. Neuropsychiatr Dis Treat. 2016;12:1761-1767. doi:10.2147/NDT.S100307

72. Zhang M, Inocente CO, Villanueva C, et al. Narcolepsy with cataplexy: does age at diagnosis change the clinical picture? CNS Neurosci Ther. 2020. doi:10.1111/cns.13438

73. Aran A, Einen M, Lin L, Plazzi G, Nishino S, Mignot E. Clinical and therapeutic aspects of childhood narcolepsy-cataplexy: a retrospective study of 51 children. Sleep. 2010;33 (11):1457-1464. doi:10.1093/sleep/33.11.1457

74. Inocente $\mathrm{CO}$, Lavault $\mathrm{S}$, Lecendreux $\mathrm{M}$, et al. Impact of obesity in children with narcolepsy. CNS Neurosci Ther. 2013;19 (7):521-528. doi:10.1111/cns.12105

75. Poli F, Pizza F, Mignot E, et al. High prevalence of precocious puberty and obesity in childhood narcolepsy with cataplexy. Sleep. 2013;36(2):175-181. doi:10.5665/sleep.2366

76. Ponziani V, Gennari M, Pizza F, Balsamo A, Bernardi F, Plazzi G. Growing Up with Type 1 narcolepsy: its anthropometric and endocrine features. J Clin Sleep Med JCSM off Publ Am Acad Sleep Med. 2016;12(12):1649-1657. doi:10.5664/jcsm.6352

77. Cremaschi RC, Hirotsu C, Tufik S, Coelho FM. High fatigue frequency in narcolepsy type 1 and type 2 in a Brazilian Sleep Center. Sleep Med. 2018;52:234. doi:10.1016/j.sleep.2018.08.013

78. Barateau L, Chenini S, Evangelista E, Jaussent I, Lopez R, Dauvilliers Y. Clinical autonomic dysfunction in narcolepsy type 1. Sleep. 2019;42:12. doi:10.1093/sleep/zsz187 
79. Plazzi G, Moghadam KK, Maggi LS, et al. Autonomic disturbances in narcolepsy. Sleep Med Rev. 2011;15(3):187-196. doi:10.1016/j.smrv.2010.05.002

80. Rocchi C, Placidi F, Del Bianco C, et al. Autonomic symptoms, cardiovascular and sudomotor evaluation in de novo type 1 narcolepsy. Clin Auton Res off J Clin Auton Res Soc. 2020;30 (6):557-562. doi:10.1007/s10286-020-00718-w

81. Jagadish S, Singer W, Kotagal S. Autonomic dysfunction in childhood hypersomnia disorders. Sleep Med. 2021;78:43-48. doi:10.1016/j.sleep.2020.11.040

82. Nordstrand SEH, Juvodden HT, Viste R, et al. Obesity and other medical comorbidities among NT1 patients after the Norwegian H1N1 influenza epidemic and vaccination campaign. Sleep. 2020;43:5. doi:10.1093/sleep/zsz277

83. Inocente CO, Gustin M-P, Lavault S, et al. Depressive feelings in children with narcolepsy. Sleep Med. 2014;15(3):309-314. doi:10.1016/j.sleep.2013.08.798

84. BaHammam AS, Alnakshabandi K, Pandi-Perumal SR. Neuropsychiatric correlates of narcolepsy. Curr Psychiatry Rep. 2020;22(8):36. doi:10.1007/s11920-020-01159-y

85. Alasim H, AlQazlan S, Albanyan S, et al. Comorbid psychiatric disorders among patients with narcolepsy. Sleep Breath Schlaf Atm. 2020;24(2):629-636. doi:10.1007/s11325-019-01890-8

86. Barateau L, Lopez R, Chenini S, et al. Depression and suicidal thoughts in untreated and treated narcolepsy: systematic analysis. Neurology. 2020;95(20):e2755-e2768. doi:10.1212/WNL.000000 0000010737

87. Chen T-Y, Huang C-H, Chung C-H, et al. Sex and age differences in the association between anxiety disorders and narcolepsy: a nationwide population-based case control study. $J$ Affect Disord. 2020;264:130-137. doi:10.1016/j.jad.2019.12.010

88. Dahmen N, Becht J, Engel A, Thommes M, Tonn P. Prevalence of eating disorders and eating attacks in narcolepsy. Neuropsychiatr Dis Treat. 2008;4(1):257-261.

89. Fortuyn HAD, Swinkels S, Buitelaar J, et al. High prevalence of eating disorders in narcolepsy with cataplexy: a case-control study. Sleep. 2008;31(3):335-341. doi:10.1093/sleep/31.3.335

90. Quaedackers L, van Gilst MM, van Mierlo P, et al. Impaired social functioning in children with narcolepsy. Sleep. 2019;42:2. doi:10.1093/sleep/zsy228

91. Lee M-J, Lee S-Y, Yuan -S-S, et al. Comorbidity of narcolepsy and depressive disorders: a nationwide population-based study in Taiwan. Sleep Med. 2017;39:95-100. doi:10.1016/j.sleep.2017.07.022

92. Almeneessier AS, Al-Jebrin S, Labani R, et al. Medical specialty visits and diagnoses received by Saudi patients prior to a diagnosis of narcolepsy. Sleep Breath Schlaf Atm. 2019;23 (2):603-609. doi:10.1007/s11325-019-01807-5

93. Fortuyn HAD, Lappenschaar MA, Furer JW, et al. Anxiety and mood disorders in narcolepsy: a case-control study. Gen Hosp Psychiatry. 2010;32(1):49-56. doi:10.1016/j.genhosppsych.20 09.08.007

94. Rocca FL, Pizza F, Ricci E, Plazzi G. Narcolepsy during Childhood: an Update. Neuropediatrics. 2015;46(3):181-198. doi:10.1055/s-0035-1550152

95. Dauvilliers Y, Paquereau J, Bastuji H, Drouot X, Weil J-S, ViotBlanc V. Psychological health in central hypersomnias: the French Harmony study. J Neurol Neurosurg Psychiatry. 2009;80 (6):636-641. doi:10.1136/jnnp.2008.161588

96. Li X, Sanford LD, Zong Q, et al. Prevalence of depression or depressive symptoms in patients with narcolepsy: a systematic review and meta-analysis. Neuropsychol Rev. 2020. doi:10.1007/ s11065-020-09443-7

97. Kim J, Lee G-H, Sung SM, Jung DS, Pak K. Prevalence of attention deficit hyperactivity disorder symptoms in narcolepsy: a systematic review. Sleep Med. 2020;65:84-88. doi:10.1016/j. sleep.2019.07.022
98. Oosterloo M, Lammers GJ, Overeem S, de Noord I, Kooij JJS Possible confusion between primary hypersomnia and adult attention-deficit/hyperactivity disorder. Psychiatry Res. 2006;143 (2-3):293-297. doi:10.1016/j.psychres.2006.02.009

99. Modestino EJ, Winchester J. A retrospective survey of childhood ADHD symptomatology among adult narcoleptics. $J$ Atten Disord. 2013;17(7):574-582. doi:10.1177/1087054713480033

100. Posar A, Visconti P, Blunda V, Pizza F, Plazzi G. Autism spectrum disorder and narcolepsy: a possible connection that deserves to be investigated. Front Psychiatry. 2020;11:265. doi:10.3389/ fpsyt.2020.00265

101. Prihodova I, Dudova I, Mohaplova M, Hrdlicka M, Nevsimalova S. Childhood narcolepsy and autism spectrum disorders: four case reports. Sleep Med. 2018;51:167-170. doi:10.1016/j.sleep.2018.07.017

102. Ohayon M A Longitudinal Study of 322 Individuals with Narcolepsy. 2012:S21-S21.

103. Pigeon WR, Pinquart M, Conner K. Meta-analysis of sleep disturbance and suicidal thoughts and behaviors. J Clin Psychiatry. 2012;73(9):e1160-1167. doi:10.4088/JCP.11r07586

104. Ortega-Albás JJ, López-Bernabé R, Als G, Gómez JRD. Suicidal ideation secondary to sodium oxybate. J Neuropsychiatry Clin Neurosci. 2010;22(3):352r.e26-352.e26. doi:10.1176/ jnp.2010.22.3.352.e26

105. Cremaschi RC, Hirotsu C, Tufik S, Coelho FM. Chronic pain in narcolepsy type 1 and type 2 - an underestimated reality. J Sleep Res. 2019;28(3):e12715. doi:10.1111/jsr.12715

106. Dauvilliers Y, Bayard S, Shneerson JM, Plazzi G, Myers AJ, Garcia-Borreguero D. High pain frequency in narcolepsy with cataplexy. Sleep Med. 2011;12(6):572-577. doi:10.1016/j. sleep.2011.01.010

107. Rieger M, Mayer G, Gauggel S. Attention deficits in patients with narcolepsy. Sleep. 2003;26(1):36-43.

108. Bayard S, Croisier Langenier M, Cochen De Cock V, Scholz S, Dauvilliers Y. Executive control of attention in narcolepsy. PLoS One. 2012;7(4):e33525. doi:10.1371/journal.pone.0033525

109. Posar A, Pizza F, Parmeggiani A, Plazzi G. Neuropsychological findings in childhood narcolepsy. J Child Neurol. 2014;29 (10):1370-1376. doi:10.1177/0883073813508315

110. Szakács A, Hallböök T, Tideman P, Darin N, Wentz E. Psychiatric comorbidity and cognitive profile in children with narcolepsy with or without association to the H1N1 influenza vaccination. Sleep. 2015;38(4):615-621. doi:10.5665/sleep.4582

111. Dorris L, Zuberi SM, Scott N, Moffat C, McArthur I. Psychosocial and intellectual functioning in childhood narcolepsy. Dev Neurorehabilitation. 2008;11(3):187-194. doi:10.1080/17518420802011493

112. Janssens KAM, Quaedackers L, Lammers GJ, et al. Effect of treatment on cognitive and attention problems in children with narcolepsy type 1. Sleep. 2020;43:12. doi:10.1093/sleep/zsaa114

113. Rosenberg R, Kim AY. The AWAKEN survey: knowledge of narcolepsy among physicians and the general population. Postgrad Med. 2014;126(1):78-86. doi:10.3810/pgm.20 14.01.2727

114. Black J, Reaven NL, Funk SE, et al. The Burden of Narcolepsy Disease (BOND) study: health-care utilization and cost findings Sleep Med. 2014;15(5):522-529. doi:10.1016/j.sleep.2014.02.001

115. Flores NM, Villa KF, Black J, Chervin RD, Witt EA. The Humanistic and Economic Burden of Narcolepsy. J Clin Sleep Med JCSM off Publ Am Acad Sleep Med. 2016;12(3):401-407. doi:10.5664/jcsm.5594.

116. Carls G, Reddy SR, Broder MS, et al. Burden of disease in pediatric narcolepsy: a claims-based analysis of health care utilization, costs, and comorbidities. Sleep Med. 2020;66:110-118. doi:10.1016/j.sleep.2019.08.008 
117. Lima FCB, Do Nascimento EB Junior, Teixeira SS, Coelho FM, da Oliveira GP. Thinking outside the box: cataplexy without narcolepsy. Sleep Med. 2019;61:118-121. doi:10.1016/j. sleep.2019.03.006

118. Thorpy M, Pasta D, Cisternas M, et al. Predictors of time to narcolepsy diagnosis in participants with adult onset of symptoms: results from the nexus narcolepsy registry. Sleep. 2018;41: A236-A236. doi:10.1093/sleep/zsy061.635

119. Giannoccaro MP, Sallemi G, Liguori R, Plazzi G, Pizza F. Immunotherapy in Narcolepsy. Curr Treat Options Neurol. 2020;22(1):2. doi:10.1007/s11940-020-0609-7

120. Donjacour CEHM, Aziz NA, Overeem S, Kalsbeek A, Pijl H, Lammers GJ. Glucose and fat metabolism in narcolepsy and the effect of sodium oxybate: a hyperinsulinemic-euglycemic clamp study. Sleep. 2014;37(4):795-801. doi:10.5665/sleep.3592
121. Latorre D, Kallweit U, Armentani E, et al. T cells in patients with narcolepsy target self-antigens of hypocretin neurons. Nature. 2018;562(7725):63-68. doi:10.1038/s41586-018-0540-1

122. Lecendreux M, Churlaud G, Pitoiset F, et al. Narcolepsy Type 1 is associated with a systemic increase and activation of regulatory T cells and with a systemic activation of global T cells. PLoS One. 2017;12(1):e0169836. doi:10.1371/journal.pone.0169836

123. Zhang Z, Mayer G, Dauvilliers Y, et al. Exploring the clinical features of narcolepsy type 1 versus narcolepsy type 2 from European Narcolepsy Network database with machine learning. Sci Rep. 2018;8(1):10628. doi:10.1038/s41598-018-28840-w

\section{Publish your work in this journal}

Nature and Science of Sleep is an international, peer-reviewed, open access journal covering all aspects of sleep science and sleep medicine, including the neurophysiology and functions of sleep, the genetics of sleep, sleep and society, biological rhythms, dreaming, sleep disorders and therapy, and strategies to optimize healthy sleep.
The manuscript management system is completely online and includes a very quick and fair peer-review system, which is all easy to use. Visit http://www.dovepress.com/testimonials.php to read real quotes from published authors. 